\title{
Research on Status Quo of Recycling and Reusing of Scrapped Vehicles and Countermeasures for Energy Saving - Based on the Analysis of Wuhan
}

\author{
Cai Huil, a, Gu Xin 2,b, , ,Fu Hongming ${ }^{3, c}$, Gao Jixin ${ }^{4, d}$, \\ Kou Yiqun ${ }^{5, e}$ and Wei Xiaoxu, \\ ${ }^{1}$ Department of Journalism and communication,Wuhan University of Technology, Hongshan \\ District,Wuhan, Hubei ,China \\ ${ }^{2}$ Department of Automotive service engineering, Wuhan University of Technology, Hongshan \\ District,Wuhan, Hubei ,China \\ ${ }^{3}$ Department of management science and information management, Wuhan University of \\ Technology, Hongshan District ,Wuhan, Hubei ,China \\ ${ }^{4}$ Department of vehicle engineering ,Wuhan University of Technology, Hongshan District ,Wuhan, \\ Hubei ,China \\ ${ }^{5}$ Department of vehicle engineering ,Wuhan University of Technology, Hongshan District ,Wuhan, \\ Hubei ,China \\ ${ }^{6}$ Department of automotive engineering ,Wuhan University of Technology, Hongshan \\ District ,Wuhan, Hubei ,China \\ a1872020360@qq.com, b1121886934@qq.com, c986009330@qq.com, d1024906054@qq.com, \\ e2432965531@qq.com, f695986190@qq.com \\ ${ }^{*} \mathrm{Gu}$ Xin
}

Keywords: Scrapped Vehicles, Recycle and Reuse, Quantitative analysis, Qualitative analysis, Unified platform.

\begin{abstract}
It is revealed that, on average, for each scrapped automobile, one ton of fuel oil, 1.8 tons of standard coal, 2.4 tons of scrap steel and $45 \mathrm{~kg}$ of non-ferrous metal can be saved. The recovery rate of end-of-life vehicles in Wuhan continues to decline, the current status of reuse is not optimistic, and research results are mostly at the theoretical level. This study quantitatively analyzed the data collected through questionnaire surveys and field surveys, and extracted five factors affecting the recovery rate of end-of-life vehicles through factor analysis and other methods: policy orientation, economic benefits, owner awareness, recycling network, operating model. Qualitative analysis of data collected using in-depth interviews, and summing up the status quo of recycling of four end-of-life vehicles through grounded theoretical coding: enterprise technology encounters bottlenecks, remanufactured product specification is not up to standard, market access thresholds are too high, and public preconceptions about remanufactured products. Based on the above research, this project summarized the problems existing in the recovery and recycling of end-of-life vehicles in Wuhan, built an integrated platform for recycling and recycling of end-of-life vehicles, and included an integrated information exchange network for end-of-life vehicle recycling, and hierarchical reuse of end-of-life vehicle resources. The two aspects of the system, and make recommendations on the main body of the government, enterprises, and the public in the platform, in order to solve the current Wuhan City scrap vehicle handling problems.
\end{abstract}




\title{
报废汽车回收再利用现状及节能减排对策研究 以武汉市为例
}

\author{
蔡慧 ${ }^{1, a}$ ，顾欣 ${ }^{2, b, *}$ ，富泓茗 ${ }^{3, \mathrm{c}}$, 高吉釒金 ${ }^{4, \mathrm{~d}}$, 寇逸群 ${ }^{5, \mathrm{e}}$, 魏晓旭 ${ }^{6, \mathrm{f}}$ \\ 1武汉理工大学, 新闻传播系, 洪山区, 武汉, 湖北, 中国 \\ 2武汉理工大学, 汽车服务工程系, 洪山区, 武汉, 湖北, 中国 \\ 3 武汉理工大学, 管理科学与信息管理系, 洪山区, 武汉, 湖北, 中国 \\ 4武汉理工大学, 车辆工程系, 洪山区, 武汉, 湖北, 中国 \\ 5 武汉理工大学, 车辆工程系, 洪山区, 武汉, 湖北, 中国 \\ 6武汉理工大学, 汽车工程系, 洪山区, 武汉, 湖北, 中国 \\ a1872020360@qq.com, b1121886934@qq.com, c986009330@qq.com, \\ d1024906054@qq.com, e2432965531@qq.com, f695986190@qq.com
}

*顾欣

关键词: 报废汽车;回收再利用;定量分析;定性分析;一体化平台

摘要: 据了解, 平均每回收一辆报废汽车, 可以节约 1 吨燃料油、1.8吨标准煤, 回收 2.4 吨废 钢铁、45公斤有色金属。武汉市报废汽车回收率持续走低, 再利用现状不容乐观, 科研成果 也多处于理论层面。本研究对采用问卷调查、实地调研方式收集的数据进行定量分析, 通过 因子分析等方法提取出 5 个影响报废汽车回收率的因素：政策导向、经济收益、车主意识、回 收网络、运作模式; 对采用深度访谈方式收集的数据进行定性分析, 通过扎根理论编码等方 法总结出 4 个报废汽车再利用现状: 企业技术遭遇瓶颈、再制造产品规格不达标、市场准入门 槛过高、公众对再制造产品既有的成见。在以上研究的基础上, 总结武汉市报废汽车回收再 利用过程中存在的问题, 构建报废汽车回收再利用一体化平台, 并对平台中的行为主体政府、 企业、公众提出相应建议, 以期解决当前武汉市报废汽车处理难题。

\section{1. 引言}

2001 年 6 月 16 日，国务院颁布的《报废汽车回收管理办法》对报废汽车回收企业资格 认定条件、市场经营行为及政府各职能部门的监督管理职责等内容做了明确规定, 为报废汽 车回收管理方面的 “根本大法”。 ${ }^{[1]}$ 随着武汉市经济的发展, 2013 年至 2017 年武汉市汽车保 有量呈稳步增长态势，但大量报废汽车流失未进入正规拆解厂，回收率低下。

2008 年国家发改委正式发布《汽车零部件再制造试点管理办法》, 确定首批汽车零部件 再制造试点企业, 将开展再制造试点的汽车零部件产品范围暂定为发动机、变速器、发电机、 启动机、转向器五类产品。现阶段由于武汉市正规报废汽车数量较少, 许多科研成果停留在 理论层面, 产品附加值较低, 再制造行业缺乏活力。

针对武汉市报废汽车回收率较低、再利用现状不容乐观的问题, 本研究通过定量定性分 析给出相关建议和措施, 以期实现节能减排目标。

本研究由以下五个部分组成: 第一部分文献综述, 对比国内外报废汽车回收再利用的研 究现状; 第二部分问卷数据分析, 利用 SPSS 软件定量分析影响武汉市报废汽车回收的因素; 第三部分个人访谈数据分析, 利用 NVivo 软件定性分析武汉市报废汽车再利用现状; 第四部 分问题总结, 归纳武汉市报废汽车回收再利用出现的问题; 第五部分节能减排对策分析, 提 
出解决框架。

\section{2. 文献综述}

以欧美国家为代表的发达国家在第二次工业革命后经济快速发展，汽车普及速度较快， 对报废汽车回收利用的研究较早。Kim Nawon（2002）从影响报废汽车回收的因素入手，提 出影响报废汽车回收能否取得成效的重要因素有生产者责任延伸制、政府的的监管力度、良 好的政策和科学的登记制度。 ${ }^{[2]}$ Smink（2003）针对影响报废汽车回收因素之间的相互作用关 系进行研究, 运用生态经济学的理论, 分析了报废汽车回收、利用、处理的技术与政策措施 之间互动关系。 ${ }^{[3]}$ Aman Chitrakar (2006) 从生产源头着眼分析影响报废汽车再利用率的因 素, 提出报废汽车再利用模型应充分考虑从产品设计、生产之初直至最后废弃物处置等活动 的全周期过程。 ${ }^{[4]}$ Harold Krikke (2010) 则对报废汽车再利用的方式进行分析比较, 提出多 圈循环相比于单圈循环将会产生更大的经济效益和环境效益。

在各国的实践中，欧盟发布报废汽车回收指令，将报废车辆的回收利用纳入法制化管理 体系。日本通过颁布《汽车再利用法》明文规定再制造产品生产标准。而严格的环境保护法 规体系和产品连带责任法规使美国报废汽车带来的环境污染降到了最小。

国际上与报废汽车回收再利用相关的法律法规、政策和管理办法的不断出台对我国报废 汽车回收再利用行业的立法工作起到了一定的借鉴作用。2001 年, 国务院颁布了第 307 号令

《报废汽车回收管理办法》，为我国报废汽车回收管理方面的“根本大法”。 ${ }^{[1]} 2009$ 年 1 月 实施了《循环经济促进法》, 为循环经济的基础性文件。

在此背景下，国内学者针对现实中仍存在的回收再利用问题提出了不同的见解。孙鹤行 (2012) 构建了以生产商和分销商为主的汽车报废回收模式, 将整个供应链的利益考虑在内, 并用算例分析了不同模式下生产商、分销商及供应链的利润。 ${ }^{[7]}$ 秦训鹏（2013）搭建了基于 产品全生命周期理论的汽车逆向产业链, 并提出了再利用方面 “再使用、再制造、再循环” 的三种利用方式。 ${ }^{[8]}$ 陈铭 (2014) 分析比较了国内外的报废汽车回收具体管理法规, 提出了 较为完备的上海市报废汽车零部件回收管理体系。 ${ }^{[9]}$ 赵璐（2017）提出回用件分类分级管理 概念及方法，构建回用件分类分级管理标准体系。

以上文献大多从报废汽车回收再利用的某一环节或行为主体展开研究, 对于武汉市报废 汽车回收再利用的行业发展具有一定的参考意义, 但缺少基于回收再利用宏观层面和微观层 面三个行为主体的整体考量。相比于既有文献, 本研究的创新主要有以下三个方面:

（1）基于武汉市汽车保有量稳步增长的现状, 调查报废汽车回收再利用问题并提出解决 方案, 具有一定的现实性。

(2) 利用 SPSS 软件定量分析问卷数据得出影响报废汽车回收的因素, 运用 NVivo 软件 定性分析访谈内容总结报废汽车再利用现状, 而非简单的现象描述, 具有一定的真实性和科 学性。

（3）本研究构建了报废汽车回收再利用一体化平台, 为解决报废汽车回收再利用率低下 问题提供新的思路和对策, 并针对平台中的行为主体政府、企业、公众提出相应建议, 从宏 观到微观, 思考角度较为全面。

\section{3. 武汉市报废汽车回收现状及影响报废车回收率的定量分析}

\section{1 武汉市报废汽车回收现状}

由湖北省统计局数据可知, 2017 年武汉市经正规处理的报废汽车数量约为 12550 辆, 仅 占当年全市报废汽车数量的 $32 \%$, 大量报废汽车流失，未进入正规拆解厂，如图 2 所示。 


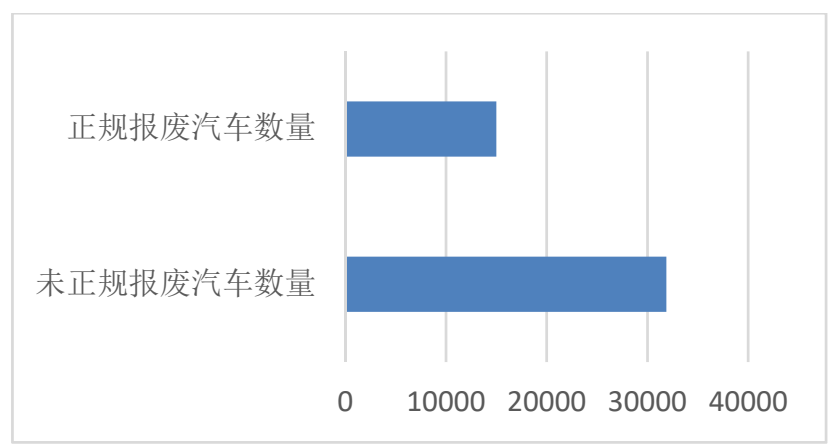

图1 武汉市报废汽车流向统计

为保护被调研企业信息的私密性, 本研究以 $\mathrm{A} 、 \mathrm{~B} 、 \mathrm{C}$ 分别代指武汉市拥有报废汽车回收 拆解资质的三家企业。在实地调研中，本研究了解到除 $\mathrm{C}$ 企业外，其余两家企业均以人工拆 解方式为主, 整体拆解方式比较落后。且由于回收报废汽车数量较少, 企业常出现 “吃不饱” 的现象。

表1 武汉市三大报废汽车回收拆解企业现状统计表

\begin{tabular}{|c|c|c|c|c|c|c|c|}
\hline 回收拆解企业 & 报废汽车类型 & 拆解方式 & 数量 & 比重 & 合计数量 & 年拆接能力 & 生产能力利用率 \\
\hline \multirow{3}{*}{ A企业 } & 试验车（无统计） & 流水线作业 & 4500 & $45 \%$ & \multirow{3}{*}{10000} & \multirow{3}{*}{30000} & \multirow{3}{*}{$33.30 \%$} \\
\hline & 出租车 & 人工 & 4000 & $40 \%$ & & & \\
\hline & 社会车辆 & 人工 & 1500 & $15 \%$ & & & \\
\hline \multirow{3}{*}{ B企业 } & 社会车辆 & 人工 & 2400 & $60 \%$ & \multirow{3}{*}{4000} & \multirow{3}{*}{10000} & \multirow{3}{*}{$40 \%$} \\
\hline & 单位公车和罚没车 & 人工 & 800 & $20 \%$ & & & \\
\hline & 武钢内部车辆 & 人工 & 800 & $20 \%$ & & & \\
\hline \multirow{2}{*}{ C企业 } & 社会车辆 & 流水线作业 & 4500 & $90 \%$ & \multirow[t]{2}{*}{5000} & \multirow[t]{2}{*}{50000} & \multirow[t]{2}{*}{$10 \%$} \\
\hline & 其它车辆 (无统计) & 流水线作业 & 500 & $10 \%$ & & & \\
\hline
\end{tabular}

\section{2 影响报废汽车回收率的因素分析}

本研究采用文献综述的方法, 得出影响我国报废汽车回收率的 16 个因素如表 2 所示。本 研究以 16 个影响因素为基础设计问卷, 通过问卷调查的方式分析影响武汉市报废汽车回收率 的因素。根据 16 个因素设置的问题选项均采用李克特五级量表，分"非常不同意"、"不同意"、 "不一定"、"同意"、"非常同意"五种不同程度的陈述，依次记为 “1、2、3、4、5”。

表 2 影响我国报废车回收率因素表

\begin{tabular}{cc}
\hline 编号 & 影响我国报废车回收率的因素 \\
\hline X1 & 回收价格 \\
X2 & 车主收入水平 \\
X3 & 汽车价位 \\
X4 & 报废手续 \\
X5 & 监管力度 \\
X6 & 对零部件再利用的限制 \\
X7 & 财政补贴 \\
X8 & 回收物流体系 \\
X9 & 回收模式 \\
X10 & 汽车制造商参与 \\
X11 & 信息管理系统 \\
X12 & 行业机构的配合 \\
X13 & 市场营销与宣传推广 \\
X14 & 车主环保意识 \\
X15 & 车主法律意识 \\
X16 & 车主安全意识 \\
\hline X
\end{tabular}

各变量的均值大多在 3.3 左右, 说明车主对各题目选项的说法处于 “一般认同” 和 “比 较认同”之间; 且标准差统计量显示较大, 说明不同车主对于各题目选项认同程度存在较大 差异。利用 SPSS 22.0 软件对样本数据进行检验后, 根据测向纯化的标准, 删除 X03、X06。 对余下题项的样本数据进行因子分析适用性检验, KMO 值为 0.712 , Bartlett 球度检验的伴随 
概率值 $0.000<0.05 ，$ 适合进行因子分析。

采用主成分分析法, 通过观察计算结果所得出的因子碎石图如图 3 所示，决定提取 5 个 因素, 累计总方差贡献率为 $85.475 \%$ 。采用方差最大法, 经 6 次迭代收玫, 因子分析结果见 表3。

表 3 因子旋转矩阵

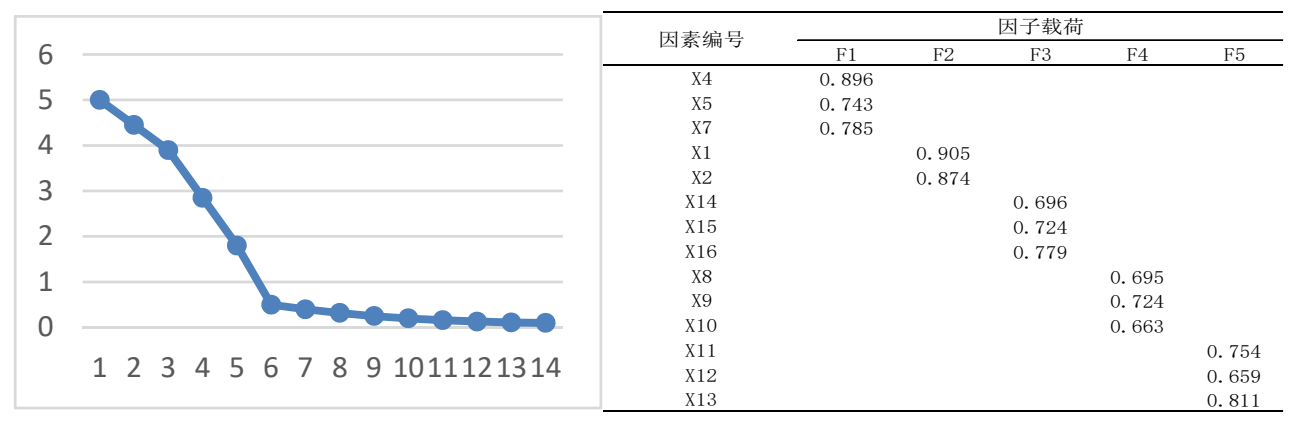

图 2 因子碎石图

因子分析共提取了五个因子（14 个因素）。第 1 个因子 F1 与变量 X04、X05、X07 关系 紧密, 命名为政策因素; 第 2 个因子 F2 与变量 X01、X02 关系紧密, 命名为经济因素; 第 3 个因子 F3 与变量 X14、X15、X16 关系紧密, 命名为车主意识因素; 第 4 个因子 F4 与变量 X08、X09、X10 关系紧密，命名为回收网络因素；第 5 个因子 F5 与变量 X11、X12、X13 关系紧密, 命名为运作模式因素。五个影响报废汽车回收率的因素按照重要程度依次递减的 顺序分别为：政策因素、经济因素、车主意识因素、回收网络因素, 运作模式因素。

\section{4. 武汉市报废汽车再利用现状及报废车资源再利用的定性分析}

\section{1 武汉市报废汽车再利用现状}

本研究采用实地调研和文献综述的方法, 得出武汉市报废汽车拆解程序和组成成分。如 图 4、图 5 所示。

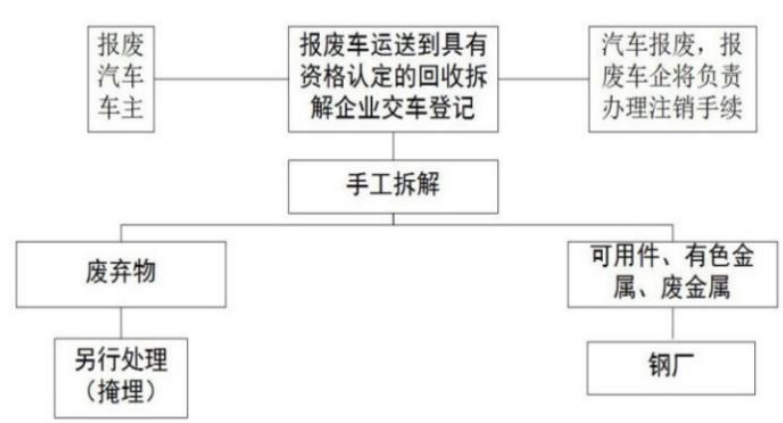

图 3 武汉市报废汽车拆解程序

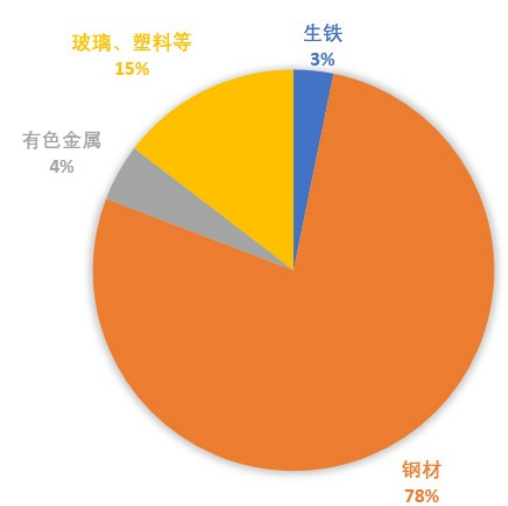

图 4 武汉市报废汽车拆解组成成分

由图 4 可知, 武汉市报废汽车拆解将车体主要分成两种方式处理一一掩埋和回炉。根据 2001 年实施的《报废汽车回收管理办法》规定, 报废汽车的 “五大总成” 不能进行市场流通, 必须作为废金属回炉, 导致报废汽车残值低。 ${ }^{[1]}$ 由图 5 所示, 钢材在报废汽车拆解成分中占 
比最高，依照目前汽车回收再利用现状直接销售钢厂，企业利润点较低。

\section{2 定性分析一扎根理论编码}

本研究针对 20 名企业技术人员及车主进行个人访谈, 旨在报废汽车再利用的现状。在 NVivo 软件的基础上, 运用三角验证法和扎根理论三层编码 ${ }^{[11]}$ 分析访谈数据, 信度效度较高。 20 份个人访谈资料中一二级编码的参考点数和材料来源如表 4 所示。

表 4 二二级编码的参考点数和材料来源

\begin{tabular}{|c|c|c|c|}
\hline 二级编码 & 一级编码 & 参考点数 & 材料来源 \\
\hline \multirow{4}{*}{ 技术瓶颈 } & 人工拆解为主 & 12 & 7 \\
\hline & 拆解方式粗糙 & 25 & 20 \\
\hline & 新技术投入成本较高 & 17 & 9 \\
\hline & 变废为宝的技术瓶颈 & 19 & 12 \\
\hline \multirow{4}{*}{ 供需市场 } & 黄牛破坏市场秩序 & 13 & 5 \\
\hline & 钢材价格波动较大 & 19 & 17 \\
\hline & 再制造产品附加值低 & 17 & 9 \\
\hline & 国外同类产品的竞争 & 9 & 5 \\
\hline \multirow{4}{*}{ 公众意识 } & 旧不如新 & 13 & 8 \\
\hline & 质量问题 & 25 & 11 \\
\hline & 安全隐患 & 37 & 15 \\
\hline & 更信任国外产品 & 14 & 13 \\
\hline \multirow{4}{*}{ 产品标准 } & 产品生命周期 & 9 & 2 \\
\hline & 安全性能检验 & 16 & 4 \\
\hline & 再利用标准 & 7 & 3 \\
\hline & 五大总成资源的浪费 & 18 & 5 \\
\hline
\end{tabular}

(1) 技术瓶颈编码参考点数 73 。人工拆解为主的方式成本较高, 且拆解方式较为粗䊅。 原有的拆解流程遇到技术瓶颈，而新技术的投放则需要大量资金支持。

（2）供需市场编码参考点数 58 。钢材价格波动较大、再制造产品附加值较低依次被提 及 19 次、17 次, 在市场因素中占主导因素。且内有黄牛市场的冲击, 外有国外同类产品的 竞争，再制造产品市场竞争压力大。

（3）公众意识编码参考点数 89 。其中安全隐患和质量问题是其担忧的主要层面，旧不 如新和更信任国外产品的观念也是其中较为重要的因素。公众对本国再制造产品的成见依然 很深。

（4）产品标准编码参考点数 50。开放五大总成和产品安全性能的检验至关重要, 而提 高再制造产品生产的标准又是延长其生命周期的重要举措之一。

\section{5. 报废汽车回收再利用过程中存在的问题}

根据问卷调查、深度访谈、实地调研所采集到的现象数据和后期运用社会学理论分析、 数据处理的结果, 将制约武汉市报废汽车回收再利用行业在节能环保、资源回收领域进一步 发展的问题归结如下:

\section{1 报废汽车回收过程中存在的问题}

（1）税收政策不合理。由于武汉市报废汽车回收企业尚未形成规模，未能引起政府有关 部门的重视, 回收拆解企业需要交纳 $17 \%$ 的增值税, 缺少进项税额抵扣, 再生资源利用成本 较高, 影响了报废汽车回收拆解企业的积极性, 经营规模不断萎缩, 市场活力不足。

(2) 车主收益过低。目前武汉市暂未对报废汽车车主进行补贴, 也未对报废汽车回收价 格设置合理的价格标准, 按照废铁重量计价的算法所获收益远低于非法中介, 正规报废汽车 
回收价格低，车主参与积极性较低。

（3）政府监管不足。武汉市大量非法拆解企业利用高价诱使车主选择非法中介进行虚假 违规报废，再通过私自贩卖国家禁止出售的 “五大总成” 等汽车配件或是拼凑私车等方式获 取高额利润。网络信息时代, 市场瞬息万变, 政府监管力度很难跟上市场经济发展的速度。

(4) 企业宣传不足。武汉市所有正规报废汽车回收拆解企业官方咨询平台都无法在网络 上找到, 非法中介充斥网络。由于缺乏实际报废流程的信息获取渠道, 武汉公众潜意识认为 报废流程复杂, 主动参与报废汽车回收积极性降低。

（5）公众意识不足。由于法律意识的缺失，部分车主尚未意识到报废汽车违规处理后新 车将无法上牌的问题; 对于报废汽车违规上路、非法拆解将会导致的安全、环保隐患的意识 不够。因此，在选择报废模式的时候，公众大多趋向于选择收益最大的报废方法。

\section{2 报废汽车资源再利用过程中存在的问题}

(1) 企业发展活力不足。武汉市现有汽车零部件再制造企业规模普遍不大, 企业发展缺 乏资金投入、人才培养和技术支持。

(2) 环境保护与盈利间的矛盾。报废汽车及其零部件在再制造环节存在着环境污染问题, 如处理不当, 会对环境造成不可逆转的负面影响, 而正规回收拆解企业建设标准高、投入大, 成本过高, 环境保护和企业盈利之间存在较大的冲突矛盾。

(3) 再制造行业标准不完善。武汉市报废汽车再利用零部件数量多而散乱, 行业缺乏对 报废汽车回用件统一的认定标准和成形的管理体系。

（4）再制造产品市场准入门槛过高。由于武汉市报废汽车 “五大总成” 必须作为废金属 回炉，大量零部件再利用率低下，没有正规合法的渠道进入市场。

（5）再制造产品缺乏市场。国内消费者对再制造产品的既有成见和国外同类产品的竞争 使得再制造产品缺乏国内国外市场。

\section{6. 节能减排对策和建议分析}

基于以上分析, 本研究利用报废汽车逆向物流理论 ${ }^{[12]}$, 构建了报废汽车回收再利用一体 化平台, 以打通回收和再利用两大过程中的发展瓶颈, 形成一条完整的报废汽车回收再利用 逆向物流绿色产业链, 如图 6 所示。

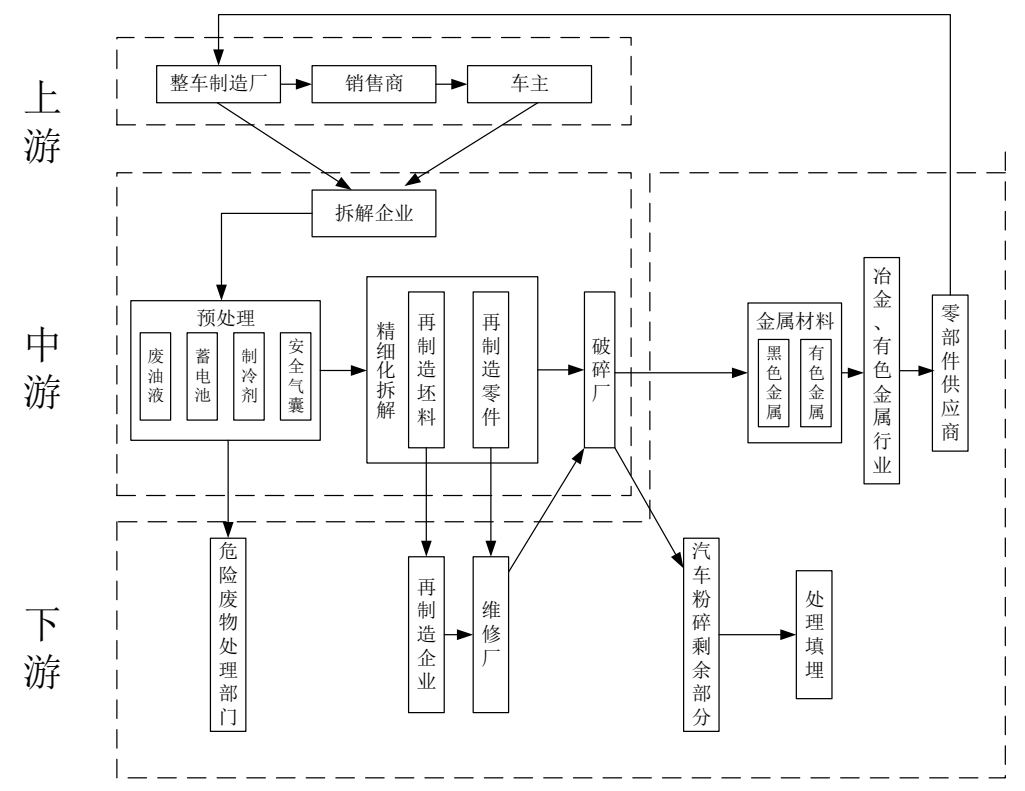

图 5 报废汽车回收再利用一体化平台 
具体来说, 报废汽车回收再利用一体化平台的功能有:

（1）信息一体化一一传统的信息交互模式效率低下，造成了报废车辆注销信息的丢失， 大量报废车超期服役或是流入黑市。实现汽车从生产销售、登记注销、报废拆解到再利用全 过程的的信息公开化，便于政府部门管理、市场内部协调和公众监督。

（2）流程一体化一一传统的再制造企业信息技术的闭塞，生产规格和质量不符合市场需 求, 缺乏市场竞争力。从上游生产销售链着手, 完善中游报废拆解的行业规范, 整合下游再 利用产业生产标准, 便于形成一套完整的武汉市报废汽车回收再利用产业链, 提高行业整体 竞争力。

\section{1 报废汽车回收难题的解决措施}

为有效解决报废汽车回收再利用过程中出现的难题, 推动报废汽车回收再利用一体化平 台功能的实现, 本研究针对两个过程中的三方行为主体提出以下建议。

(1) 政府政策和监管方面

落实汽车生产者责任延伸制度。鼓励汽车生产企业通过开发可回收性技术、易拆解性技 术、环保材料替代技术, 编制汽车拆解指导手册等方式直接参与报废汽车回收再利用过程, 从生产源头提高报废汽车可回收率。

建立报废汽车回收管理网络，加强对报废汽车的监督管理。政府有关部门应密切配合， 从报废汽车的注销登记、路面巡查等环节强化对报废汽车的监督管理, 杜绝 “假过户”、“假 转籍”、“假异地报废”现象的发生。

确定合理报废汽车回收价格，制定阶段性补贴政策及税收政策。放开报废汽车回收价格 参照谱, 恢复市场报价使回收价格趋于合理; 制定相应补贴政策及税收政策, 并阶段性实施, 对报废汽车回收产业产生刺激作用。

提高报废汽车回收企业资格认定的标准，强化对认定企业的动态监管。改变资格认定终 身制, 结合汽车保有量的发展变化和地域特点, 对报废汽车回收拆解企业进行统筹规划, 合 理布局。

（2）报废汽车回收企业方面

加强产学研合作，提高企业技术水平。企业应响应国家号召，引进先进设备并积极主动 创新, 提高资源回收利用率, 改变当前以人工拆解为主现状, 实现流水化、数字化、信息化 作业。

推广车主送车报废简易流程，提高企业运营效率。在吸取先进的技术理念后，企业应构 建功能完善、流程简洁、一站式服务平台, 向车主主动提供预约收车服务, 并对此类模式加 以推广，实现信息公开化。

导入多元媒介刺激, 提升公众对报废汽车的认识。要以绿色消费为核心, 利用新媒体, 加大对汽车报废重要性的宣传力度, 普及报废汽车回收流程知识, 塑造企业社会良好形象。

（3）公众意识和行为方面

公众加强自我环保意识和安全意识, 树立节能减排理念。公众应意识到报废汽车对环境 和交通安全的危害。

公众积极了解政府相关政策。公众应时刻关注报废汽车相关政策，主动将报废汽车送到 正规汽车报废厂，将良好的环保态度转化为实际行动。

公众行使自身监督权。由于报废汽车回收拆解行业依然存在许多非法现象, 在发现非法 汽车拆卖、小厂拆解、小店重装和黄牛市场高价抬卖等非法行为时, 公众应主动向有关部门 举报，发挥公民监督权的作用，为汽车报废回收行业营造良好的环境。

\section{2 报废汽车再利用难题的解决措施}

（1）政府立法和政策方面 
政策扶持再制造业的发展。税收减免和人才、技术、资金扶持，建设再制造产业示范基 地，促进产业集聚发展。

废除现行政策中五大总成件只能通过破碎、回炉方式进行循环利用的规定。从法规层面 允许五大总成件能够参与再利用环节，放开市场准入限制。

完善再制造产品标准体系。重视报废汽车再利用的质量标准体系建设, 确保再制造产品 规格符合要求，为重塑公众对再制造产品的信任感、规范市场行为创造条件。

(2) 报废汽车再制造企业方面

企业分级分类处理经过回收企业预处理后的报废汽车。遵循再使用、再制造、再循环三 个阶段形成汽车生产、再制造、维修企业的生产原料，提高再利用率。

树立行业自律精神。严格遵守法律规定的再利用排污标准和产品规格等关键考核指标, 规范汽车零部件再利用销售渠道, 承担社会责任的同时塑造企业良好形象。

加大对再制造业的宣传。注重进一步普及公众环保意识和对报废汽车再利用产品的正确 认识, 促进行业的进一步发展。

(3) 公众意识和行为方面

抛弃传统的 “旧不如新” 思想，与时俱进，支持符合社会历史发展潮流的新事物，推动 本国再制造业的发展。

加强自我环保意识同时主动宣传并使用再制造产品，营造资源再利用的社会氛围。

针对再制造行业出现的产品瑕疵和规格不达标现象, 行使公民自身监督权, 推动行业自 我优化和水平的提高。

\section{致谢}

本研究为武汉理工大学大学生节能减排社会实践与科技竞赛《报废汽车回收再利用现状 及节能减排对策分析一一以武汉市为例》项目的阶段性成果之一, 研究构建了报废汽车回收 再利用一体化平台, 对解决武汉市和其他省市的报废汽车回收再利用难题都具有一定的参考 意义, 但缺少实证研究, 后续研究中可以加以考虑。

\section{References}

[1] National People's Congress Standing Committee. Measures for the Administration of Retirement of End-of-Life Vehicles [S].

[2] Nawon K. Exploring Determinant Factors for Effective End-of-Life Vehicle Policy. IIIEE Report, 2002, 7: 324-331.

[3] Smink C, Koppen, C. S, et al. Ecological modernization theory and the changing dynamics of the European automotive industry: the case of Dutch end-of-life vehicle policies. International Journal of Environment \& Sustainable Development, 2003, 2(3): 288-304.

[4] Chitrakar A,Liu F,Cao H,et al. A model for end-of-life vehicles management based on green manufacturing. Journal of Chongqing University, 2006, 5(1): 1-7.

[5] Krikke H. Opportunistic versus life-cycle-oriented decision making in multi-loop recovery: an eco-eco study on disposed vehicles. The International Journal of Life Cycle Assessment, 2010, 15(8): 759-768.

[6] National People's Congress Standing Committee. People's Republic of China Circular Economy Promotion Law[S]. 
[7] Sun Hexing. Research on Reverse Logistics Recovery Mode and Network Structure of Scrapped Vehicles [D]. Shanxi: Shanxi University, 2012.

[8] Qin Xunpeng, Wu Chengwu, Han Jingwei, et al. Automobile's reverse industry chain based on the product life cycle theory [J]. Ecological Economy (Academic Edition),2013,(1):287-290.

[9] Chen Ming and Wang Junjun. Recycling of scrapped cars - regulations, management and outlook. Journal of Shanghai Jiaotong University, 2014(01): 125-131.

[10]Zhao Lu and Qin Xunpeng. Classification, Grading Management and Reuse of Reused Automobile Recycling Parts. Logistics Technology.2017(12): 7-11.

[11]Luo Hongwei,Ding Wu. A Study on the Emotional Factors of the Zero-study Phenomenon in Open English Education-A Qualitative Based on NVivo research report [J].Journal of Open Education.2011.17(6):98-103.

[12] Liu Xiangting, Qian Xiaoying. Research on Reverse Logistics System of Automobile Recovery Industry [J].2007,(7):42-44. DOI:10.3969/j.issn.1003-8434.2007.07.021. 